\title{
ICOASST - INTEGRATING COASTAL SEDIMENT SYSTEMS
}

Robert J. Nicholls, ${ }^{1}$ Andy Bradbury ${ }^{3}$, Helene Burningham ${ }^{2}$, Justin Dix ${ }^{4}$, Michael Ellis ${ }^{5}$, Jon French ${ }^{2}$, Jim W. Hall ${ }^{6}$, Harshinie U. Karunarathna ${ }^{7}$, Jonathan Lawn ${ }^{1}$, Shunqi Pan ${ }^{8}$, Dominic E. Reeve ${ }^{7}$, Benedict Rogers ${ }^{9}$, Alejandro Souza ${ }^{10}$, Peter K. Stansby ${ }^{9}$, James Sutherland ${ }^{11}$, Owen Tarrant ${ }^{12}$, Michael Walkden ${ }^{13}$ and Richard Whitehouse ${ }^{11}$.

\begin{abstract}
UK coasts are subject to widespread erosion in part due to the cumulative effect of human intervention on soft coastlines, and further threatened due to more rapid change due to climate change, especially sea-level rise. At the same time, Shoreline Management now requires predictions of coastal evolution up to 100 years in the future. This leads to the challenge of predicting coastal geomorphic behaviour at the mesoscale $\left(10^{1}\right.$ to $10^{2} \mathrm{~km}$ and $10^{1}$ to $10^{2}$ years). Currently, this is often based on expert judgement. However, relevant components for mesoscale coastal simulation are emerging, including: (1) new methods for system-level analysis of coast, estuary and offshore landform behaviour, which include engineering and management interventions in a consistent manner to natural drivers; (2) well validated 'bottom-up' hydrodynamic and sediment transport models such as POLCOMS and TELEMAC; (3) operational 'reduced complexity models' of selected coastal landforms (e.g., cliffs (SCAPE), estuaries (ASMITA), saltmarsh (SLAMM)); and (4) growing observational datasets that allow data-driven approaches to coastal analysis and prediction. The iCOASST Project will use these components to develop and apply an integrated systems modelling framework for mesoscale coastal simulation as explained in this paper.
\end{abstract}

Keywords: coastal management, sediment transport, erosion, reduced complexity models, climate change impacts.

\section{INTRODUCTION}

Coastal areas in England and Wales are at greater risk of flooding and erosion than their landward equivalents. To address these hazards, over the last 20 years, a process to develop long-term Shoreline Management Plans (SMPs) has been developed (Leafe et al., 1998; Cooper et al., 2002; DEFRA, 2006). The spatial boundary of SMPs is defined by coastal cell and sub-cell boundaries (of order $10^{2} \mathrm{~km}$ ), and in temporal terms they consider the implications of coastal change, including climate change, up to 100 years into the future. Hence, SMPs operate at the mesoscale $\left(10^{1}\right.$ to $10^{2} \mathrm{~km}$ and $10^{1}$ to $10^{2}$ years): collectively the 22 Second Generation SMPs (e.g., Suffolk Coastal District Council, 2010) cover the entire coastline of England and Wales.

Analysis of coastal hazards increasingly stresses the natural protective (or buffer) function of coastal geomorphic systems such as beaches, dunes and saltmarshes in preventing or reducing flooding and erosion. When considering the long timescales considered in an SMP, the future of this protective function is called into question. Erosion is already a widespread phenomenon due to long-term negative sediment budgets, often exacerbated by human interference. In the future, climate change is an additional major concern that will almost certainly enhance erosional trends. The resulting degradation of geomorphic systems could greatly exacerbate erosion and flood risks. Currently, expert judgement is often the main approach to appraise these issues. Hence, there is a fundamental need to improve mesoscale geomorphic predictions across all the drivers of change, including the geomorphic influence of potential mitigation options.

\footnotetext{
${ }^{1}$ Faculty of Environment and Engineering and Tyndall Centre for Climate Change Research, University of Southampton, Highfield, Southampton, Hants, SO17 1BJ, UK

2 UCL Department of Geography, University College London, Gower Street, London, WC1E 6BT, UK

${ }^{3}$ Channel Coast Observatory, National Oceanographic Centre, European Way, Southampton, SO14 3ZH, UK

${ }^{4}$ National Oceanographic Centre, University of Southampton, European Way, Southampton, Hants, S014 3ZH, UK

${ }^{5}$ British Geological Survey, Environmental Science Centre, Nicker Hill, Keyworth, Nottingham, NG12 5GG, UK

${ }^{6}$ Environmental Change Institute and Tyndall Centre for Climate Change Research, University of Oxford, South Parks Road, Oxford, OX1 3QY, UK

${ }^{7}$ College of Engineering, Swansea University, Singleton Park, Swansea, SA2 8PP, Wales, UK

${ }^{8}$ Cardiff School of Engineering, University of Cardiff, Cardiff, Wales, CF10 3XQ, UK

${ }^{9}$ School of Mechanical, Aerospace and Civil Engineering and Tyndall Centre for Climate Change Research, University of Manchester, Manchester, M13 9PL, UK

${ }^{10}$ National Oceanographic Centre, Joseph Proudman Building, 6 Brownlow Street, Liverpool, L3 5DA, UK

${ }^{11} \mathrm{HR}$ Wallingford, Howbery Park, Wallingford, Oxfordshire, OX10 8BA, UK

${ }^{12}$ Flooding and Communities, Environment Agency, Horizon House, Deanery Road, Bristol, BS1 5AH, UK

${ }^{13}$ Royal Haskoning DHV, Stratus House, Emperor Way, Exeter, EX1 3QS, UK
} 
The iCOASST integrating coastal sediment systems project addresses this challenge with the overall aim of improving our capability to predict long-term and regional scale morphodynamic change on the open coasts and in the estuaries of the UK to support erosion and flood risk management. This is a fundamental research challenge, including issues such as (1) understanding and describing the diversity of complex interacting geomorphic systems, (2) understanding the role of the long-term sediment budget, especially quantifying small net sediment fluxes within much larger gross sediment fluxes, and (3) including the role of human agency on the coast which now often acts as a 'geological' process shaping geomorphic evolution. However, important foundations have been laid that can provide a platform for a significant improvement in this situation as explained below. By adopting a hybrid methodology based on these foundations, the authors belief that significant progress is possible, and these insights could be rapidly applied to practise. This paper outlines the background and planned methodological approach of the iCOASST project.

\section{BACKGROUND AND PREVIOUS RESEARCH}

Concepts of sediment mass conservation and the sediment budget are crucial to the understanding of landform dynamics (Thorn and Welford 1994). In the case of coastal systems, the sediment cell (Inman and Frautschy 1966) has proved an invaluable concept for the estimation of sediment budgets (French 2004) and as a geomorphological framework for management, including SMPs (Motyka and Brampton 1993). However, the cell concept has significant limitations, especially on more open coasts where boundaries are harder to identify. Moreover, conventional cells are ill-suited to the representation of broad-scale linkages between estuarine, coastal and offshore systems (Cooper and Pontee 2006) or long-range suspended sediment pathways, which operate at multiple scales (e.g., Keen and Slingerland 1993). There is thus a need to formulate a conceptual model that better integrates open coasts with estuaries, incorporates sediment pathways for fine-grained as well as beach-grade material, and which considers sediment exchanges with the coastal shelf (French et al. 2010). Such a model must be validated (wherever possible) with reference to sediment transport studies and/or physically-based modelling (Amoudry and Souza 2011).

Various approaches have been used for predictive modelling of mesoscale coastal morphodynamics. Whilst 'bottom-up' process-based analyses, which couple hydrodynamic and sediment transport models, are attractive in terms of their physical principles and widespread applicability (e.g. Amoudry and Souza 2011; de Vriend et al. 1993), they work best for well-constrained problems with limited space- and time- horizons. These time limits have encouraged experimentation with semi-empirical parameterizations to represent form-process linkages at a broader scale. This so-called 'reduced complexity' (RC) approach is now commonplace in geomorphology (Murray and Paola 1994; Coulthard et al. 2002) but has been less applied to coastal landforms. A coastal example is the SCAPE (Soft Cliffs And Platform Evolution) model (Dickson et al. 2007; Walkden and Hall 2005), which demonstrates a broader range of emergent behaviours and responses to sea-level rise than are predicted by equilibrium 'top down' models such as the Bruun rule of shoreline erosion. Cellular or raster-based models, which are based on the concept of cellular automata, have also been applied to coastal landscape and ecosystem change (de Kok et al. 2001; Hibma et al. 2003), but with the exception of preliminary work by Dearing et al (2006), have not been widely applied to problems with a strong geomorphological aspect. One model with considerable potential in this respect is SLAMM (Sea Level Affecting Marshes Model) (Clough and Park 2007), which simulates intertidal shoreline modifications and habitat conversions in response to sea-level rise. In addition, systematic coastal monitoring has become universal around England, producing steadily growing observational datasets that increasingly allow data-driven approaches to coastal analysis and prediction.

Despite the progress described above, we cannot yet predict the morphological evolution of coastal systems at the mesoscale $\left(10^{1}\right.$ to $10^{2} \mathrm{~km}$ and $10^{1}$ to $10^{2}$ years) that are most relevant to the management decisions, including climate change impacts. Particular challenges include the need for more integrated conceptual frameworks and predictive models that are able to represent the full range of coastal types, and protocols and frameworks for coupling models of estuary, coastal and offshore systems. In the UK, there have been significant earlier research efforts to draw on such as the Tyndall Coastal Simulator (Mokrech et al., 2009; Nicholls et al., 2013) and the Estuaries Research Programme (http://www.estuary-guide.net/estuaries_research.asp). This suggests the need for approaches that bring together formalised knowledge of coastal systems with the quantified broad scale analysis that 'bottom-up' hydrodynamic and sediment transport models can provide, and with the systems insights from a new generation of reduced complexity models.

\subsection{The iCOASST Project}

The UK National Environmental Research Council (NERC) has funded a four-year research project to develop a new approach to the conceptualisation and modelling of integrated coastal sediment systems. The project is known as "iCOASST integrating coastal sediment systems", and will be delivered by a consortium of 
six universities, three national research organisations, and two other organisations, in partnership with our stakeholders, the Environment Agency (EA) (who are the operational coastal authority in England and Wales).

The lead is the University of Southampton; with partners Swansea University, University of Manchester, University of Oxford, Cardiff University, University College London (UCL), National Oceanographic Centre (NOC) in Liverpool, British Geological Survey and HR Wallingford. We have sub-contracted both Royal HaskoningDHV and the Channel Coast Observatory (CCO): the latter are responsible for coastal monitoring in England.

The overall goal is to develop and implement a hierarchical modelling framework for mesoscale coastal change. Central to this proposed system is a new generation of behavioural landform models capable of coupled application at regional scales to resolve key feedbacks between climate forcing, sediment supply, morphology and erosion and flood risk. However, implementation of such models requires rigorous characterisation of the landform components and their relationships in terms of energy and mass (sediment) fluxes. Coastal systems mapping based on a range of inputs can characterise the relationships between coastal elements and features. Coastal area models, supported by empirical analyses of shelf bathymetry and substrate, also provide a quantitative basis to understand these linkages. Figure 1 shows how these three levels of abstraction will interact within the overall modelling framework.

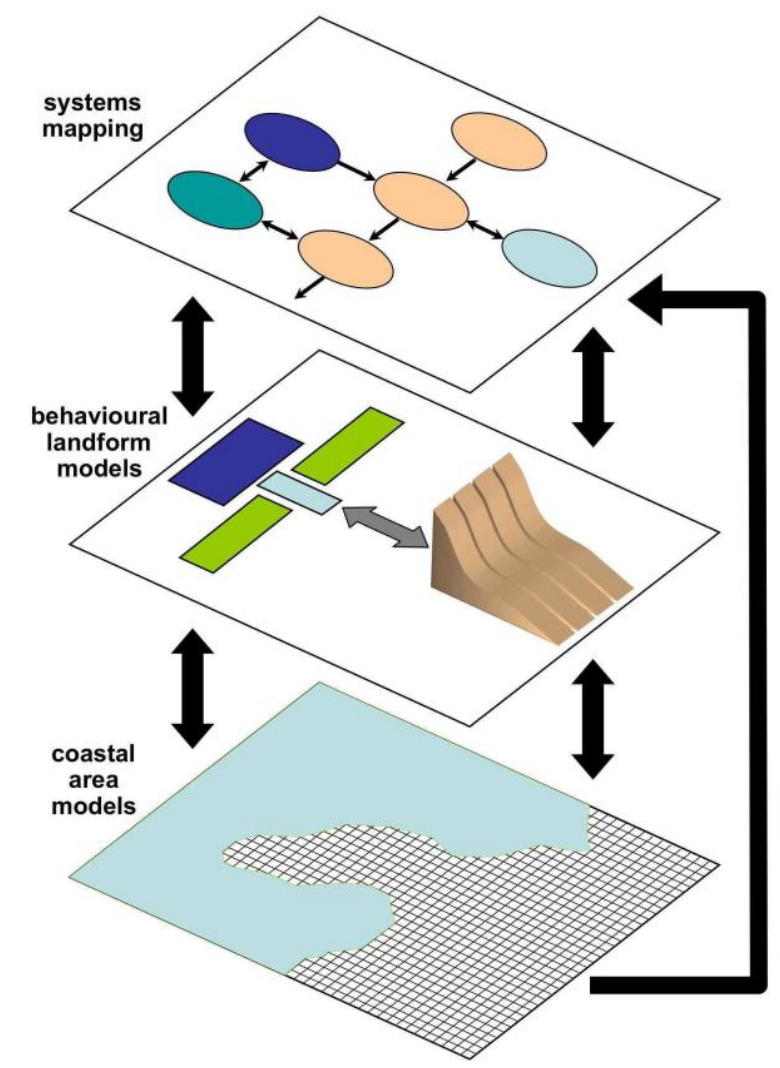

Figure 1: The interaction of coastal systems mapping, reduced complexity landform models and coastal area models within the proposed iCOASST framework.

System uncertainty, model linking, testing and validation are of critical importance. The research is structured into deliverables as explained in Section 3, with component work packages. All the software developed within iCOASST will be open source and, where relevant, be OpenMI compliant. This will maximise the legacy of the project, including application to coastal erosion and flood management.

\subsection{Aims and Objectives}

The iCOASST project addresses the need for new methods to characterise and forecast long term coastal geomorphic system evolution, building on the following foundations

1. New methods for system-level analysis of coast, estuary and offshore landform behaviour

2. Empirical analysis of the growing time series of coastal change

3. Operational reduced complexity models of selected coastal landforms 
4. Appropriate coupling of these within a community modelling framework to provide probabilistic assessments of coastal change at a regional scale.

The iCOASST project will exploit these emerging insights to accomplish a fundamental improvement in our ability to analyse geomorphic systems by addressing the following issues:

1. A Systems Modelling Framework that can both supersede the coastal cell/sub-cell approach currently used in shoreline management planning and provide a transparent evidence-based framework for more quantitative modelling

2. Development of and reduced complexity and data-driven Behavioural Geomorphic Models to enable simulation of coupled coastal-estuary-offshore landform behaviour at the mesoscale

3. Validation and Application of the coupled framework to explore the sensitivities of selected coastal regions to changes in sediment supply resulting from sea-level rise, climate change and coastal management scenarios

In partnership with the EA it is planned that there will be a rapid take-up of the methods developed in practise, and this aspect of delivery is explicitly identified and resourced though the project, but not considered here.

\section{PROJECT STRUCTURE AND DESIGN}

\subsection{Work Plan}

Delivery of the iCOASST objectives is being accomplished via a series of three main deliverables, subdivided into smaller work packages (WP). These are summarised in Table 1.

Table 1. iCOASST Structure

\begin{tabular}{lll}
\hline Deliverable & Work Package & Title \\
\hline 1 & \multicolumn{1}{l}{ Systems Modelling Framework } \\
1.1 & Framework Development \\
1.2 & Coastal System Mapping Methodology and Tools \\
& 1.3 & Large-scale Coastal Area Modelling \\
& 1.4 & Software System Integration \\
& Development of Behavioural Geomorphic Models \\
& 2.1 & Review and Define Priorities \\
2.2 & Behavioural (Reduced Complexity) Landform Model Development \\
& 2.3 & Statistical (Data-Driven) Model Development \\
& 2.4 & Geomorphic Model Integration \\
& Application and Validation \\
& 3.1 & Suffolk Coast (SMP7 - sub-cell 3c) \\
& 3.2 & Liverpool Bay (southern part of SMP22 - sub-cells 11a and 11b) \\
\hline
\end{tabular}

\subsection{Deliverable 1: Systems Modelling Framework}

This Deliverable is developing a systems-level understanding that incorporates the complex responses of coupled landforms to changes in hydrodynamics and sediment supply, as well as the interaction of estuarine, coastal and offshore sedimentary systems that have hitherto been studied in isolation. Whilst the systems concept has long been central to geomorphology, the idea here is to formalise scientific understanding of disparate sedimentary processes and individual landform dynamics into a consistent and standardised framework as a foundation to predictive coastal morphodynamic simulation. The systems modelling framework integrates the three very different abstractions of coastal system behaviour shown in Figure 1:

1. Coastal systems mapping (WP1.2) provides a generalised conceptual understanding and representation of the coastal system. building upon approaches developed by French, Burningham and Whitehouse (2010) and Whitehouse et al. (2009). Conceptual systems mapping is informed by analysis of sediment transport pathways using empirical analyses of offshore data and process-based area models (WP1.3).

2. Behavioural landform modelling (WP2.2, WP2.3) involves development and coupling of a range of reduced complexity (RC) and stochastic models of mesoscale landform behaviour. Whilst the approach has been demonstrated (e.g. coupling of the SCAPE (open coast) and ASMITA (estuary) models (Walkden and Rossington 2009)), it requires generalising to a wider range of landforms and their interactions.

3. Process-based coastal area modelling (WP1.3) provides understanding of hydrodynamic forcings that drive coastal change. It helps validate conceptual modelling (WP1.2) and provides boundary conditions for 
the behavioural models (WP2.2, WP2.3). Process-based modelling can also utilise downscaled outputs of GCMs and RCMs to simulate the impacts of changing climate drivers, as well as changing sediment budgets due to changing management approaches.

\subsubsection{WP 1.1 Framework Development}

This Work Package formally defines the overarching systems framework that integrates the various conceptual, behavioural and physically-based approaches outlined in Fig. 1. By integrating these three levels of abstraction, we aim to exploit their various benefits whilst circumventing their limitations. Work will begin by revisiting existing sets of definitions and formalising these into a common ontology for the project. A core set of output indicators that are relevant to coastal decision makers are being developed in consultation with coastal practitioners. These will incorporate both quantitative (e.g. shoreline position, transport rate, profile, elevation, width, volume/area change) and indicative (e.g. change of state and configuration, breaching potential, habitat transitions) indicators for geomorphic system components, presented in graphical and map form, with uncertainty estimates.

A geospatial framework for storage of information across all layers will be established in the context of the application and validation case studies undertaken in WP3.1/WP3.2. This includes structuring all three layers of information and their interaction. In common with WP1.2, we will use open source Quantum GIS (QGIS) for the geospatial elements and Python to code a minimum set of interactions between models. Meanwhile, spatial database facilities will be developed in open source PostGIS and populated with spatial datasets that span each layer in the framework (e.g. topography and aerial photos).

Links into the Environment Agency's asset management framework will be precisely defined and careful attention paid to the ways in which uncertainties, multiple scenarios and processes of change are handled at the interface the systems models and asset performance tools. This will be accompanied by guidance to enable unambiguous application of the framework.

Handling of uncertainty is fundamental and given the diversity of modelling methods adopted in this project, we identify three primary approaches:

1. Linguistic uncertainty representations are particularly appropriate for representing expert statements about epistemic uncertainty according to a common set of protocols (e.g. IPCC 2005).

2. Stochastic methods are well suited to variable quantities (e.g. water levels, wave heights) and can in some cases be propagated directly (e.g. using first order methods) in order to determine the moments of the predicted quantity. This approach has been demonstrated by Reeve and Li (2009) in relation to the modelling of bay shape.

3. Monte Carlo sampling provides a more general framework for propagation of uncertainties, albeit at some considerable numerical expense. This is the approach adopted in the Tyndall Coastal Simulator (Walkden et al 2008), where the cascade of uncertainty in climate forcing, through coastal response to natural hazards on the coast, has been analysed. However, due to its computational expense we suggest fitting non-stationary joint extreme value models in order to establish accurate probability estimates (Wu and Hall 2012). This combination of distribution fitting and judicious Monte Carlo simulation will be extended and refined in the current analysis.

The attraction of the generalised systems framework is that a common approach to uncertainty representation can be applied at each level. Our approach to sensitivity analysis will vary according to the level within the framework. At the level of coastal systems mapping, sensitivity can be explored in terms of connectivity between map entities and expert judgements of the strength of influence. Quantified analysis of the maps can provide insights into sensitivity. At the levels of behavioural systems modelling and process-based modelling, sampling-based sensitivity analyses are more appropriate (e.g. Morris or variance-based sensitivity analysis (Hall et al. 2009)). The potential to develop adjoining models that directly provide local sensitivities will be explored. There is a strong potential link with the statistical methods developed in WP2.3, particularly Canonical Correlation Analysis (CCA), which provides a direct measure of sensitivity of predictive variables to input factors (see below).

\subsubsection{WP 1.2 Coastal System Mapping Methodology and Tools}

Coastal System Mapping (CSM) is a new approach to the conceptualisation of large-scale coastal geomorphic systems based on hierarchical classification of landforms and management interventions, and the formalisation of geomorphological and engineering knowledge into a map of the interactions between them (French et al. 2010). By converting disparate sources of information ('plain data') into usable knowledge, consensus-derived system maps provide a means of understanding the multiple influences and sediment pathways that govern coastal behaviour. System maps provide a repository for quantitative sediment budget 
analyses and a framework for applying predictive numerical models. A preliminary example of a CSM for part of Suffolk is shown in Figure 2.

This Work Package is developing and operationalising the CSM methodology that was piloted to proof of concept stage by Whitehouse et al. (2009). It is refining the coastal system conceptual framework to more explicitly incorporate previous coastal system concepts, such as the 'coastal tract' concept (Cowell et al. 2003) and the Tyndall Coastal Simulator (Hanson et al. 2010). The coastal tract concept is especially useful as a 'meta morphology' that recognises processes not just in the longshore, but also in the cross-shore, including landward (e.g., estuaries and lagoons) and seaward (the inner shelf) elements. In line with our CSM methodology and the behavioural landform models being developed under Deliverable 2, the coastal tract shifts attention from simple idealised individual landform behaviour to more integrated consideration of the mutual adjustment of suites of landforms.

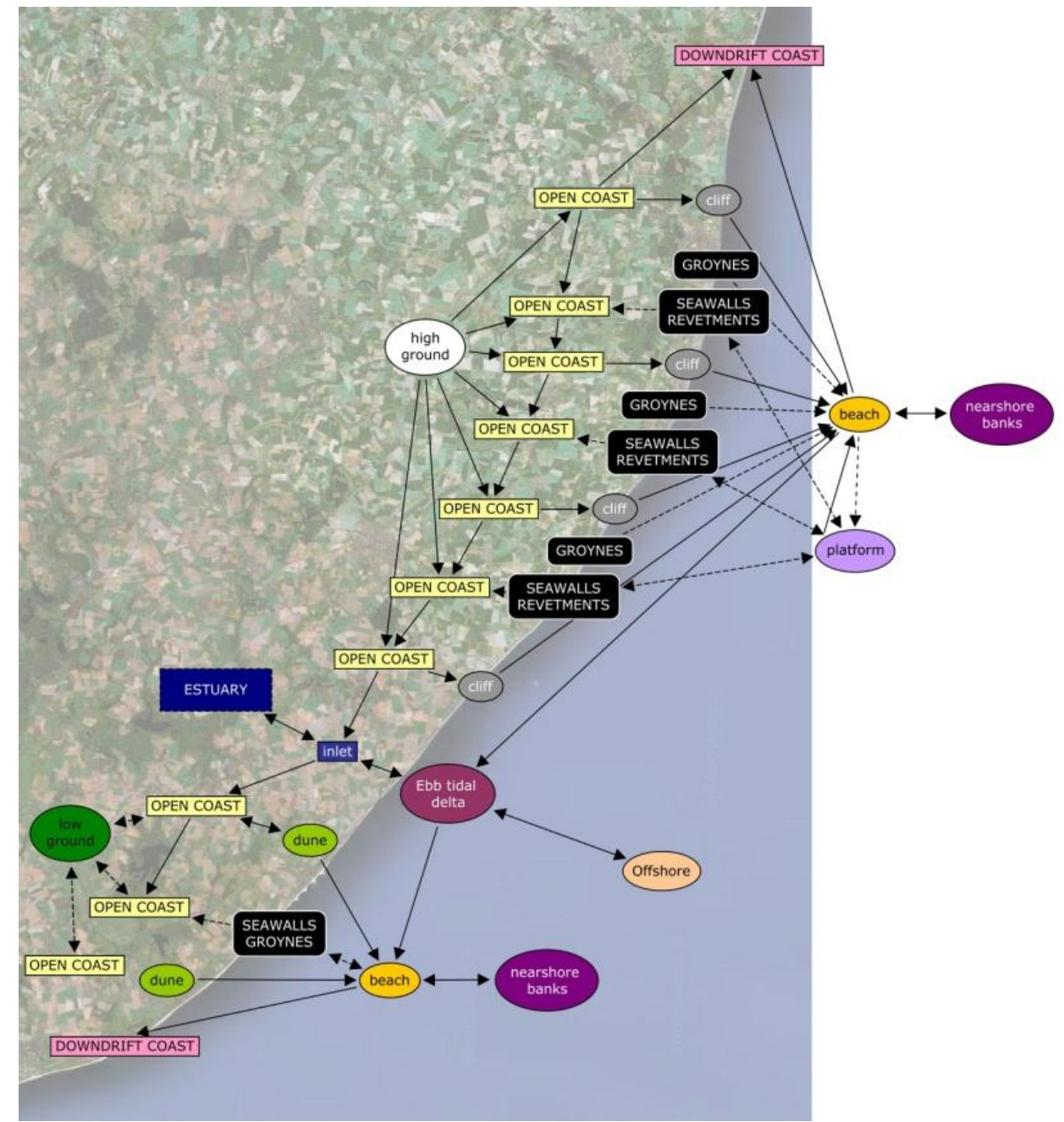

Figure 2 Early 'proof of concept' CSM for part of the Suffolk coast, eastern England (from Whitehouse et al., 2009).

The operational CSM software being developed is designed to significantly improve on our earlier 'proof-ofconcept' that made use of the CmapTools concept-mapping software originally developed for other applications (French et al. 2010). We are currently developing QGIS and Python-based components to support direct linkage to web-based background mapping (e.g. Google) or aerial imagery at hierarchical resolutions. This will facilitate GUI-based mapping of system components (landforms, structures, interventions) and links across a wider range of spatial scales. The new software will be used to analyse estuary-coast-offshore linkages for all of England and Wales, and update the Motyka and Brampton (1993) sediment cell map to support future SMP development and other broad-scale analyses. This will be informed by detailed analyses of sediment transport and hydrodynamic influence pathways derived from numerical coastal area models (WP1.3), and analysis of high resolution bathymetric and offshore substrate datasets.

In addition, new methods for directly analysing system maps will be developed. This will include analyses of connectivity, relative abundance of system components and their interactions (influences, mass fluxes), 
spatial scales of influence associated with changes imposed on a given component, and inferences of systemlevel behaviour.

\subsubsection{WP 1.3 Coastal Area Analysis}

This aims to determine long-term large-scale residual sediment pathways, and associated deposition and erosion maps, within broad coastal domains at mesoscales (e.g. Figure 3). The domains will be within the Northwest European shelf (depths $<200 \mathrm{~m}$ ). The results will both validate and feed quantitative information into the coastal system framework developed and mapped under WP1.1 and WP1.2, and provide boundary conditions for models developed in WP2.2 and WP2.3. WP1.3 is using physically-based numerical models that take into account tides, waves, wind and surge and nearshore/offshore features. Modelling is being undertaken at two levels: 1) 3D POLCOMS, including baroclinic effects; 2) 2D TELEMAC in depth-averaged form.

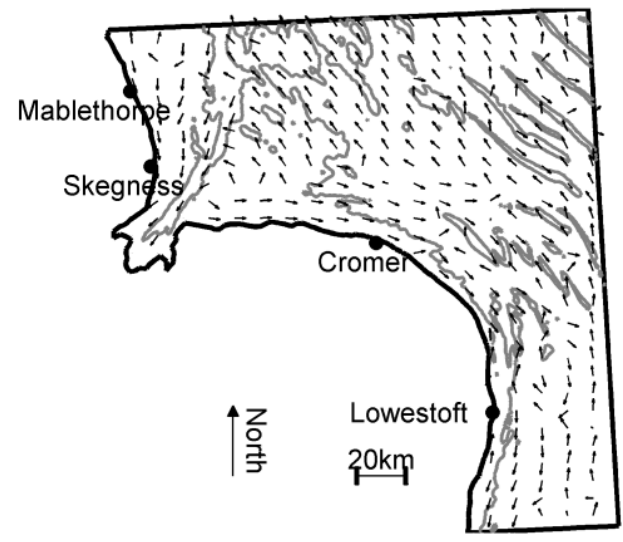

Figure 3: Example of modelled sediment pathways in the southern North Sea, including Suffolk.

POLCOMS models tides, surge, waves (Brown et al. 2010), and sediment transport (Souza et al. 2007; Amoudry et al. 2009). It has been used for the whole UK shelf on a $1.8 \mathrm{~km}$ orthogonal grid over $1-2$ years (Holt and Proctor 2008), and decadal scale interannual variability of hydrodynamics has been analysed in the Irish Sea (Brown et al. 2010). A nested grid of about $180 \mathrm{~m}$ may be implemented for the coastal domains to be analysed in WP3.1/3.2 (i.e. Suffolk coast and Liverpool Bay).

TELEMAC uses an unstructured FE mesh, and is coupled with a wave propagation module and a sediment transport module, which is regularly updated (Stansby et al. 2009). It has previously been used for smaller coastal domains at timescales up to 100yrs (Chini et al 2010a), rather than the whole continental shelf. As well as open coasts, it has been used to model the Garonne estuary (Chini and Villaret 2007).

In WP1.3, POLCOMS will use the hydrodynamics, waves and sediment fluxes o define sediment pathways and morphodynamics on a $1.8 \mathrm{~km}$ grid. This may extend into large estuaries (e.g. the Dee and the Mersey in the Liverpool Bay case study), if nested with a finer local grid. This will be valuable for locating domain boundaries in regions where flux is small, reducing uncertainty. TELEMAC will then be used to provide finer resolution around prominent features, particularly nearshore features, including wave coupling and decadal simulation. Validation against existing field data will be undertaken in WP1.2 and WP3.1/WP3.2. We will also assess the influence of waves and baroclinic processes (Souza et al. 2010) on residual pathways and fluxes via inter- and intra-model comparisons.

Within a coastal domain, the interior fluxes determine the bed movement together with the outer flux boundary conditions. These outer fluxes are determined by sources (e.g. cliffs, beaches, estuaries) both inside and beyond the domain. While it is desirable to minimise the influence of external sources by defining appropriate outer boundaries, their domain of influence is poorly known and is likely to be large for fine sediments with long suspension times (Stansby and Omar Awang 1998) (see WP1.2). These sources may be most effectively simulated at the mesoscale using RC models such as SCAPE (Chini et al. 2010b) (see WP2.2). Sources within the domain may be quantified using the RC behavioural geomorphic models developed under WP2.2 and this will be evaluated during the project. Outer boundary conditions for the coastal domain will be provided by continental shelf modelling (POLCOMS) and the inner boundary will be low water springs. Sediment fluxes within the domain will be modelled for periods of $\mathrm{O}(1 \mathrm{yrs})$ and averaged to obtain residuals. The resulting sediment flux maps will be affected by climate change and changing management (by influence on sources) and the uncertainties arising from such sensitivity will be quantified with reference to the 
framework developed in WP1.1. Validation of sediment transport pathways will be possible using the seabed substrate and bedform analysis undertaken by BGS in WP1.2

\subsubsection{WP 1.4 Software system integration}

'Community modelling' lies at the heart of model-based science that seeks to understand environmental dynamics at a system level. It is especially important in coastal sediment systems modelling as different classes of landform and interactions between estuary, coast and offshore sub-systems are best handled with different types of model. OpenMI (http://www.openmi.org) is the leading open interface standard that allows models to exchange data with each other on a time step basis. OpenMI is ideally suited to models based on different concepts, with different spatial and temporal resolutions and representations (e.g. 1D, 2D or 3D discretisation). WP1.4 delivers these aspects of system framework, model and software integration.

The provision of a robust integrated modelling interface is a necessary step towards ensuring that the new models developed within the project can be linked and run successfully. HR Wallingford has established and is lead contributor to FluidEarth (https://fluidearth.net/default.aspx), an initiative that promotes the use of OpenMI and integrated modelling. This provides a software development kit (SDK) that is available to the wider modelling community to help facilitate the uptake of OpenMI and a software tool, 'Pipistrelle' for building and running integrated models or 'compositions' consisting of linked models, which is being adopted by the OpenMI association. A generic graphical user interface (GUI) for integrated models has also been developed (San Roman Blanco, Sutherland and Harper, 2012) which will be adapted to the particular requirements of the iCOASST project, in collaboration with researchers involved with WP1.1 and WP 1.2. The adoption of OpenMI will allow iCOASST scientists to concentrate on the development, testing and rigorous validation of new integrated models (or compositions) of sediment systems. The modelling platform will allow the addition of new models and the upgrade of existing models during this project (WP1.3/2.2/2.3) and beyond.

The integrated modelling process will use a systematic approach that

1. identifies which models are to be linked via OpenMI in the first stages of the project,

2. makes each code OpenMI-compliant (if they are not already),

3. undertakes validation to ensure that the results of the integrated models are accurate and stable,

4. combines multiple linked models together where appropriate, including validation studies undertaken in Deliverable 3..

Fundamental to the iCOASST project approach is the proper treatment of uncertainty. Building on work under WP 1.1, suitable methods will be identified and developed within the GUI. Testing of the probabilistic routines will be undertaken with established sediment models. Uncertainty assessment is especially important where OpenMI is used to integrate models that previously have not been linked together dynamically.

\subsection{Deliverable 2: Development of Behavioural Geomorphic Models}

Deliverable 2 advances our capability in respect of RC and data-driven behavioural landform models. In WP2.1, defines the current capability (Murry and Paola 1994; Coulthard et al. 2002; Murray 2007), needs and realistic goals for Deliverable 2. In WP2.2, existing RC approaches are generalised, extended and coupled for application to a broader range of coastal and estuarine landform types. In WP2.3, 'data-driven' models, that use observations to find patterns of behaviour between different geomorphic variables that may then be used to predict future system behaviour (Rozynski and Jansen 2002; Rozynzki 2003; Mares and Mares 2003). Effective integration of these modelling efforts within the overall systems modelling framework (Deliverable 1) is ensured by WP2.4.

\subsubsection{WP2.1 Review and Define Priorities}

This involves assessment of coastal morphology at a hierarchy of scales; their interactions and coupling between scales; the current status of behavioural geomorphic models; and the needs and challenges posed by the two validation regions (Liverpool Bay and Suffolk). Early insights into the prevalence and role of system components from the Coastal System Mapping work will help to identify modelling priorities. The review of existing behavioural models will focus on the time and space scales at which different models currently operate and, working in collaboration with the ontology developed in WP1.1 and WP1.2, will identify the set of variables required to quantify interactions between different models.

\subsubsection{WP 2.2 Behavioural (Reduced Complexity (RC)) Landform Model Development}

Large-scale coastal and estuary system behaviour presents major modelling challenges, but thinking of them as complex systems provides an opportunity to develop new ways of capturing the interactions between the multiple component landforms and processes. Importantly, and in contrast to bottom-up approaches, this is 
consistent with the interpretive processes normally used by geomorphologists. Based on the WP2.1 priorities, WP2.2 will generalise and extend existing RC approaches and produce a set of behavioural geomorphic models capable of simulating mesoscale coastal behaviours, including aspects of the interaction between suites of landforms and between open coasts and estuaries. As a starting point, we will develop the SCAPE model (Walkden and Hall 2005). SCAPE (Figure 4) treats a soft rock coast as a set of sub-systems (shore platform, beach, cliff, talus and wave and tidal processes), discretized in a quasi-3D manner as a sequence of interlinked cross-shore profiles.

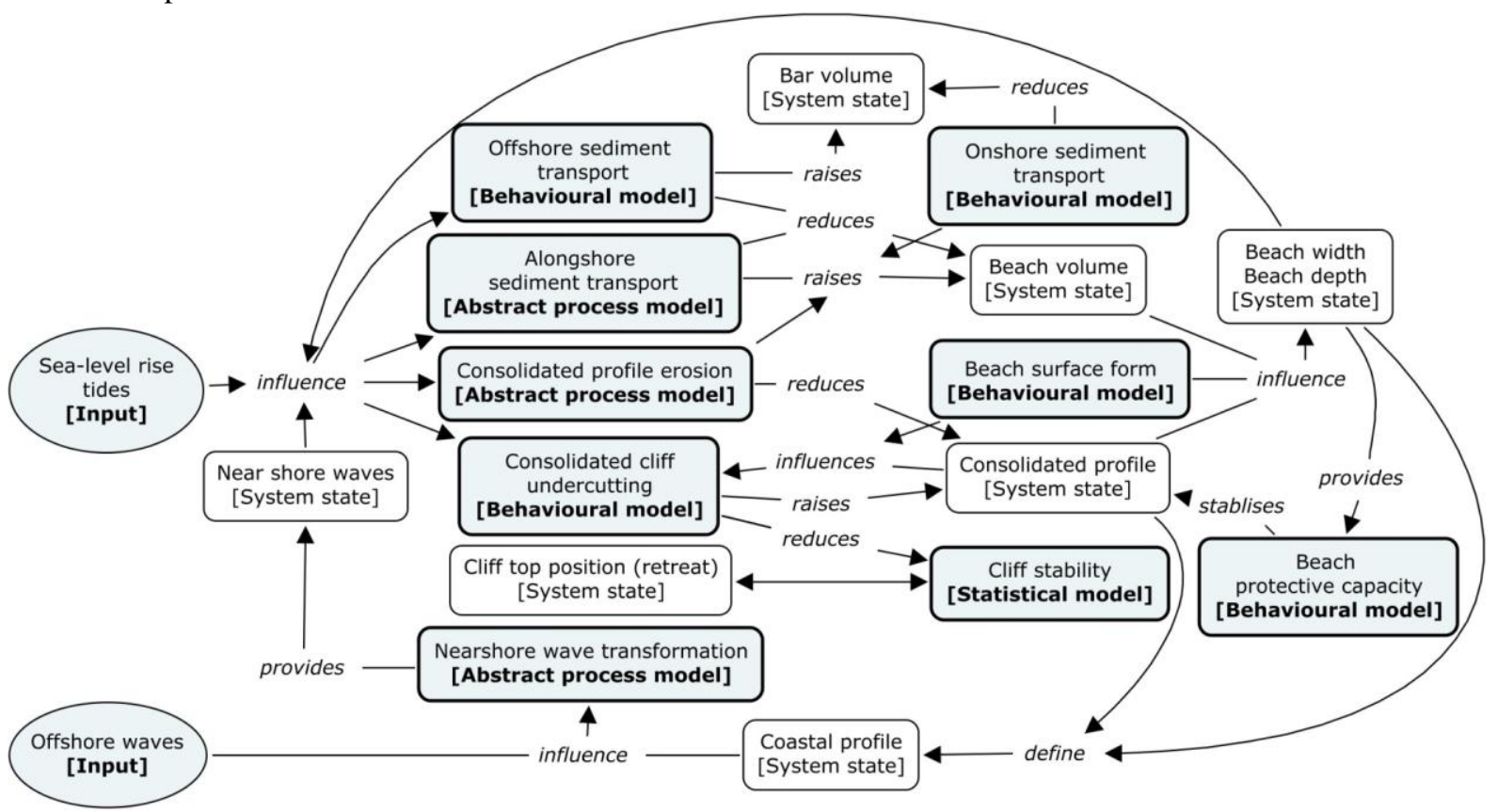

Figure 4: A schematisation of the SCAPE Reduced Complexity Model (Walkden and Hall, 2005)

Within the context of the new systems framework (WP1.1), and taking advantage of the involvement of the primary developer of SCAPE (Mike Walkdon, now with Royal Haskoning) in the team, the software architecture of the model will be modified to conserve the full range of sediment types (cohesive sediment is presently sourced from cliffs, but not conserved). The profile sub-model will then be generalised to accommodate a wider range of coastal types. To generalise mesoscale predictive methods and facilitate ready inclusion within the overall systems framework, the new models will be developed using RC systems thinking consistent with SCAPE and other RC models development. Internal interactions will be simulated to capture characteristic emergent properties of coastal elements (cf. Ashton et al. 2001; Werner 2003). Larger scale physical feedbacks between features will be simulated where this regulates coastal change (e.g. Walkden and Hall 2005; Valvo et al. 2006). Where necessary, biophysical feedbacks will be included (e.g. saltmarshes (Ruddy et al. 1998)). In this way, SCAPE-like models will be developed to include barrier beaches; dunebacked beaches; intertidal flat-saltmarsh profiles; and spits. Existing models highlighted by the scoping under WP2.1 will be considered for inclusion in whole or in part. For example, the systems-based Coastal Evolution Model (Ashton et al. 2001) will be acquired and coupled with SCAPE, to improve representation of spits and nesses. Existing empirical and statistical models will be adapted to describe variability and uncertainty (see WP2.3). To allow for representation of engineering interventions, the University of Plymouth 1-line model (which can already represent the effect of detached breakwaters on adjacent beaches; Pan et al. 2010; Wang and Reeve 2010) will be extended to deal with different groyne types. The effects of cliff retreat will also be considered (to link with SCAPE predictions).

Simulation of spatially complex changes in estuary morphology requires a different approach to model discretisation, and cellular or raster models are a more logical choice. We will build upon the raster-based SLAMM model, developed over a number of years in the USA (Clough and Park 2007). SLAMM is open source and has already been modified to better represent physical processes of sedimentation with tidal wetlands (Kirwan and Murray 2008) in addition to ecological habitat transitions. It combines a high resolution digital elevation model (usually LiDAR-derived), a GIS-classification of landform and habitat type, and a decision tree incorporating geometric and qualitative relationships to represent transitions between landform-habitat types. SLAMM is currently being evaluated at UCL for modelling estuary-scale response to sea-level rise at finer spatial resolutions ( 10 to $20 \mathrm{~m}$ ) than previously used in the US (cell sizes of 0.1 to $1 \mathrm{~km}$ or more). Building on recent UK experience with cellular models of estuarine sedimentation (Dearing et al. 2006), we will adapt the 
SLAMM approach to further improve representation of landform behaviour, especially the treatment of shoreline erosion within both open coast and fetch-limited waters, barrier beach and spit dynamics, and both subtidal and intertidal sedimentation.

In suitable test regions, for landforms mapped out in WP1.2 and boundary conditions provided by the coastal area modelling under WP1.3, coupled model simulations will be undertaken to investigate the emergent behaviour of various scales and configurations of coast-estuary system. Sensitivity testing and validation will be undertaken using the uncertainty framework developed in WP1.1).

\subsubsection{WP2.3 Statistical (Data-driven) Model Development}

Increasing observations from continuous coastal monitoring programmes can advance our understanding of medium and long-term morphological evolution. With national strategic investment in coastal monitoring, this will potentially be a major source of scientific insights and management tools in the future, and hence provide a helpful adjunct to process-based models. Such techniques are generally based on advanced statistical analysis that identifies patterns of behaviour within a dataset (e.g. Empirical orthogonal function and wavelet analysis) or between two or more separate datasets (e.g. Canonical correlation and cross-wavelet analysis). In the first case, if strong trends or cycles can be identified these can be used as the basis for forming forecasts based on suitable extrapolation. In the second case, if a strong link between two types of variable can be established, it may be possible to predict one that is difficult or expensive to measure (e.g. beach profiles) on the basis of another that is easier to measure (e.g. wave conditions). These methods have become known as 'data-driven methods' and require relatively large sets of observations (Rozynski and Jansoen 2002; Rozynski 2003) They are limited by the range of conditions contained in the measurements and by the fact they are based purely on statistical manipulations without explicit physical understanding. Methods combining elements of both statistical approaches and reduced physics approaches are beginning to be developed (e.g. behavioural inverse methods) and provide a link between the two groups of techniques. Further, empirical design relations that are widely accepted in the coastal engineering community (e.g. Dean profile, Powell shingle beach profile, static bay shape, Larson's dune erosion formula) can be extended on the basis of the observational database into stochastic forms that provide information on the expected morphology and its variability.

WP2.3 will develop a collection of methods and models that function consistently within the system framework (WP1.1). This will involve: coding empirical knowledge as a rule or equation where available; flagging gaps in knowledge appropriately; updating existing methods and models to account for variations in sediment type; representing uncertainty; and considering defence interventions. The methods will be assessed for consistency and suitable adjustments and/or rules for application developed to avoid conflicts. Our intention is to choose a selection of methods that cover equilibrium models and reduced physics models that typically apply to either a profile or plan shape, and extend these to a stochastic description. In addition we will include two data-driven techniques that can be applied to higher dimensional features as well as profiles. Specifically, we will cover the following points, subject to the guidance from WP2.1, which may change priorities:

- $\quad$ Empirical models in which the Dean, Vellinga, and Powell profiles, the Bradbury breach indicator and Bay shape formulations will be extended to deal with uncertainty.

- $\quad$ Reduced physics models (links to WP2.2) in which a behavioural inverse model (Karunarathna et al. 2008; Karunarathna et al. 2011) will be extended to include probabilistic predictions of medium-term coastal and estuarine morphology and Larson's dune erosion model will be extended to a probabilistic description.

- Data-driven models, in which uncertainty methods will be extended to include bootstrapping for Empirical Orthogonal Functions (EOF) methods in addition to established jack-knife approaches (Reeve et al 2008) and Canonical Correlation Analysis methods will be extended to forecast beach profiles from wave conditions (Horrillo-Caraballo and Reeve 2008) to 2-D features such as spits and flats.

\subsubsection{WP2.4 Geomorphic Model Integration}

The most interesting scientific insights from systems modelling emerge from interaction and feedback between system components. Moreover, the coastal systems concept that underpins iCOASST is based on the notion that long-term projections of coastal behaviour will be best modelled through integrated analysis of interacting coastal behaviours. Integration of the modelling components described in the preceding sections is therefore central to our scientific mission.

The case study locations studied in WP3.1 and WP3.2 will provide a focal point for integration and validation. WP2.4 will ensure that the models that are developed in WP2.2 and 2.3 are theoretically and technically compatible. This is a process that will be initiated in WP2.1 and will interact closely with WP2.2/2.3 and WP1.4. As models become available they will be tested in realistic settings in order to explore interdependencies and emergent properties, before embarking on application and validation at case study locations (WP3.1/3.2). 
The methods for uncertainty and sensitivity analysis (WP1.1) will be implemented in the context of these models in order to demonstrate how uncertainties propagate through systems of models to relevant predictive quantities and to identify key sensitivities. Analysis of sensitivity will help to guide the complexity of the models developed, so that effort in research and data acquisition is invested in those areas that have most influence on key predictive quantities.

\subsection{Deliverable 3: Application and Validation}

Case studies will be undertaken in two contrasting sub-cells to evaluate the ability of the results from Deliverables 1 and 2 to reproduce qualitatively correct and quantitatively useful morphodynamic behaviour at a regional scale. To explore the importance of data quality we will experiment with deliberately degrading the input data, to understand the influence on the outputs. Two contrasting sites are considered (1) the Suffolk Coast; and (2) Liverpool Bay. They are now discussed in turn.

\subsubsection{WP3.1 Suffolk Coast Validation Site}

This Site comprises SMP7 (Suffolk Coastal District Council, 2010) and corresponds to Sub-cell 3c. It extends $73 \mathrm{~km}$ from Lowestoft to Harwich in Suffolk, eastern England, and has numerous towns and villages, two nuclear power stations and a major port situated on glacial cliffs or on low lying land fronted by shingle ridges.
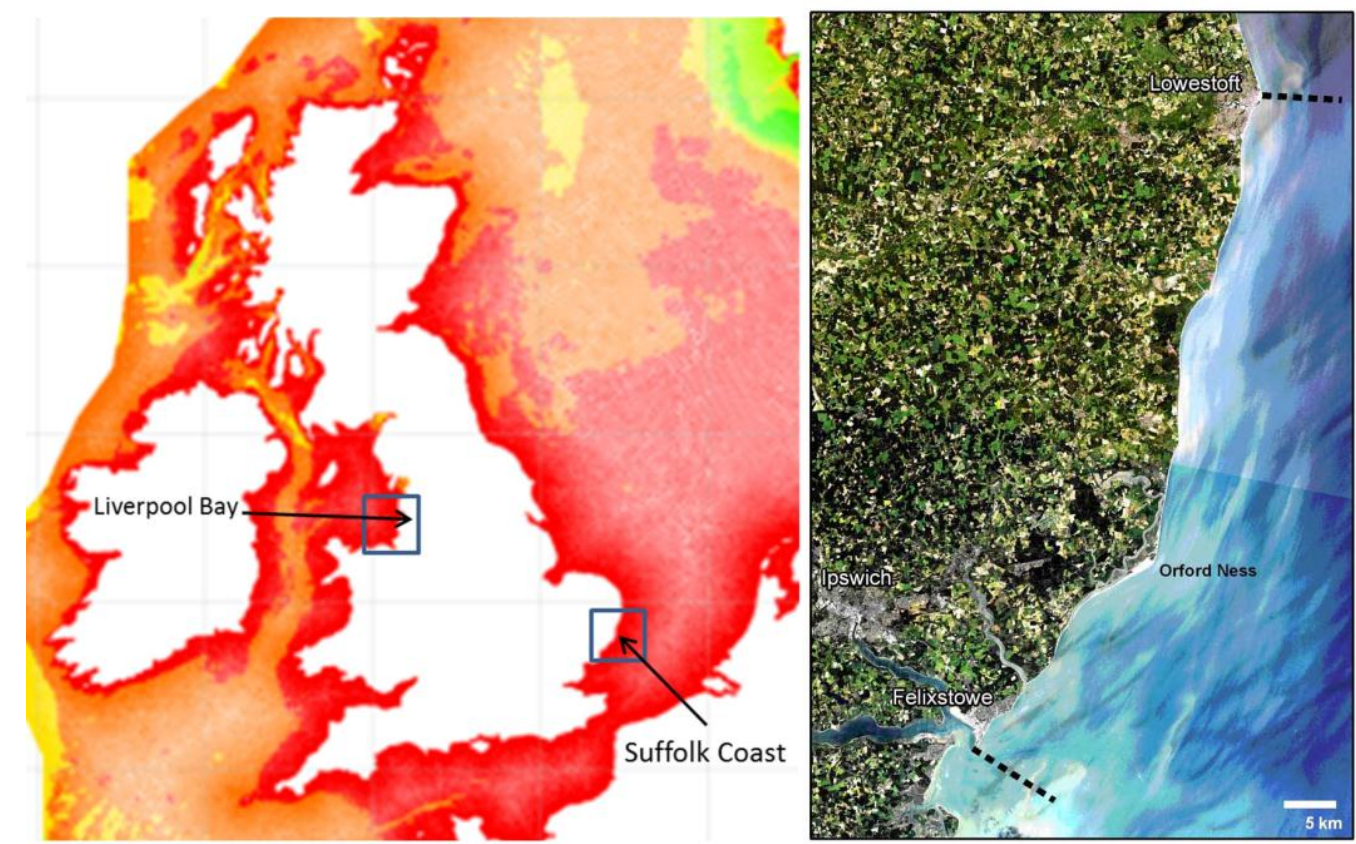

Figure 5: Suffolk Coast validation site: Lowestoft to Felixstowe. Left: Location and right: Detailed site.

This coastline featured prominently in the Southern North Sea Transport Study, and served as a test site for EA-SC006074 (Whitehouse et al. 2009). SMP7 is complex in terms of its alongshore transitions between adjacent coastal profile types. Geomorphologically, this coast is notable for the strong connections that define a more-or-less continuous littoral drift system, the presence of numerous controlling headlands and forelands (including various nesses), numerous estuaries (including the Blyth, Deben, Alde/Ore and Stour), and process links between the nearshore and offshore bank systems (Whitehouse et al. 2009).

\subsubsection{WP3.2 Liverpool Bay Validation Site}

This site comprises the southern part of SMP22 (North West and North Wales Coastal Group, 2011) and corresponds to Sub-cells 11a and 11b (Figure 6). Liverpool Bay is a macrotidal shelf sea where the regional dynamics are strongly influenced by the adjacent estuaries. Liverpool Bay is a strategic research area; it is home to the NOC Irish Sea Observatory and has hosted the NERC FORMOST and FREE COFEE projects, as well as the EU MICORE project. It is a coastal region comprising sand dunes, tidal flats, mud flats, salt marsh and hard engineering structures, where strong horizontal and vertical gradients are present. Tidal currents dominate, but it is the residual circulation (normally much weaker) that determines the fate of freshwater and suspended sediment transport. 


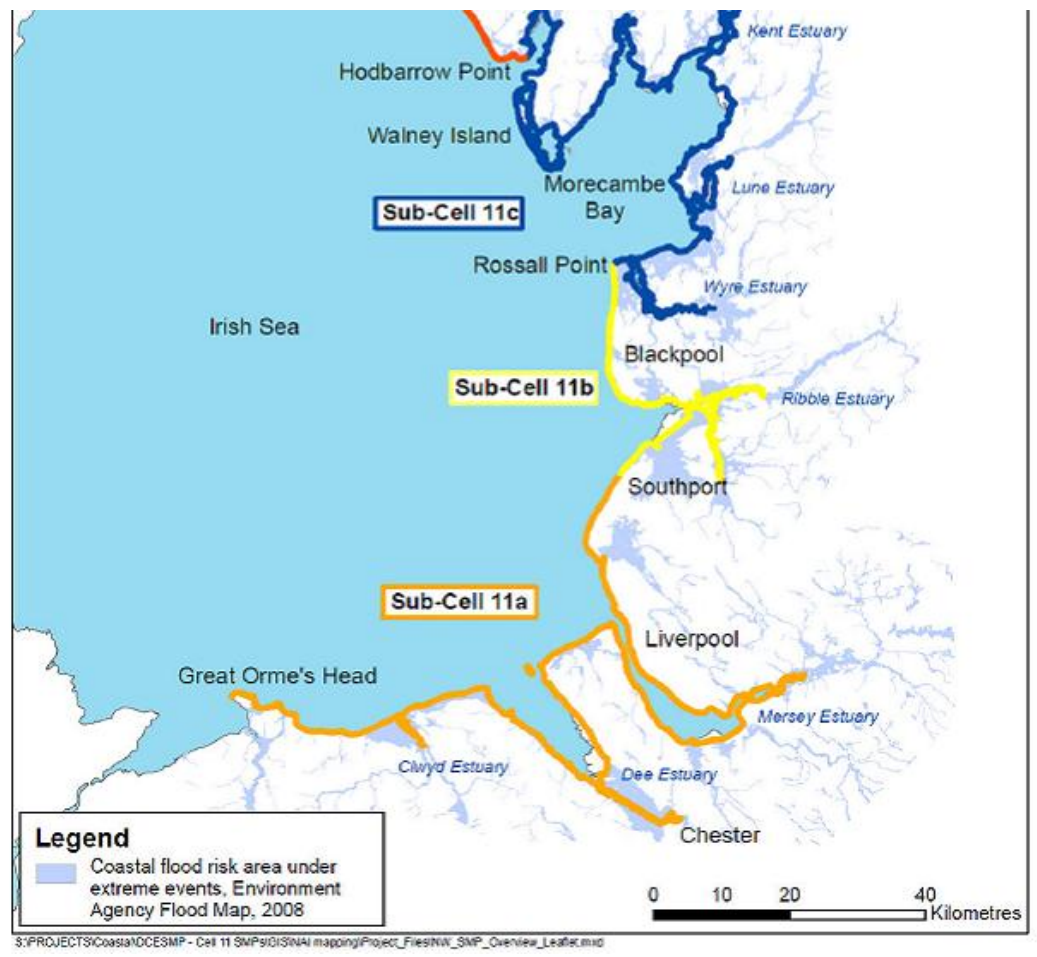

Figure 6: Liverpool Bay validation site: Great Orme's Head to Rossall Point. (For location see Figure 5).

Residual transport in estuaries coastal areas, is greatly modified by the effects of density gradients and stratification (Jay and Musiak 1994; Valle-Levinson 2008), in such a way that the sediment pathways can change direction up to $90^{\circ}$ (Souza, Lane and Betteridge 2010). This promotes sedimentation in estuaries and adjacent coasts (Burchard et al. 2008) with important morphodynamic implications.

\subsubsection{Methodology}

The application and validation activities will comprise (1) data gathering, (2) model implementation and (3) validation and scenario testing and some indicative activities are outlined below.

Data gathering. In both sites, available data will be gathered drawing extensively on public and EA datasets, as well as the Irish Sea Observatory for Liverpool Bay. This includes sea surface height, meteorology, currents and waves, bathymetry and topography, maps, charts, LiDAR and beach profiles. Extensive intertidal bathymetric and topographic data are also available for both sites. Data on beach and seabed sediment will be obtained from existing datasets, such as those collected by BGS or those collected for Shoreline Management Plans and Strategy Studies, including the composition of underlying landforms. The links between different geomorphic elements (e.g., beaches and the offshore) will be obtained from WP1.2/1.3.

Model implementation and validation. An integrated RC model of both sites will be developed using the GUI and software system (WP1.4) by linking appropriate combinations of behavioural models (WP2.2/2.3/2.4) and the data within the conceptual system framework (WP1.1/1.2). For the Suffolk Coast, a preliminary assessment suggests that this requires models of soft cliffs, eroding shore platforms, shingle beaches, spits, estuaries, offshore sandbanks and beach control structures (e.g. groynes). For Liverpool Bay, the importance of the large estuaries required their consideration and we will explore/validate a range of models of the area, such as the fine resolution hydrodynamic models (POLCOMS \& TELEMAC) of the area. This modelling will be designed to identify sediment pathways and transport rates to and from the coast for different sediment sizes. In both sites, the integrated model will be run in historic mode to validate its performance against known geomorphological development and relevant recent observations as appropriate (e.g., multi-year Lidar and XBand radar data available from the Dee Estuary and beach profiles for the Sefton coast). Initial model runs will be deterministic, but after the model has been validated, uncertainty and sensitivity testing will be undertaken using the methodologies developed in WP1.1.

Scenario testing. This will include the development of future scenarios of storminess and sea-level rise, such as from UKCP09 (Lowe et al. 2009), and different scenarios of management intervention developed with the EA and other relevant practioners. Hence, we will use the models to simulate future coastal evolution at both sites for these scenarios, including the range of uncertainty. This will be used to identify future trajectories of 
coastal morphological evolution, including consideration of their possible effects on flood and coastal erosion risk. Selected results with be archived by the Channel Coastal Observatory.

\section{CONCLUDING REMARKS}

The iCOASST Project is designed to be both scientifically innovative in terms of predicting mesoscale coastal geomorphic evolution and to provide practical tools and methods to support Shoreline Management Planning. It is founded on a hybrid and novel methodology that draws on and integrates several distinct, but related areas of knowledge. In terms of scientific innovation it aims to provide a number of advances, including:

1. Integrating three approaches into a coherent systems modelling framework for decadal prediction (including all grain sizes)

2. Capturing and exploring interaction/coupling in coastal systems and understanding emergent behaviour

3. Exploring a community modelling framework to maximise the legacy of the project.

The foundations of success are apparent in existing demonstration activities, but successful development and application of the proposed model framework will represent a major scientific achievement.

\section{ACKNOWLEDGEMENTS}

iCOASST integrating coastal sediment systems, is funded by UK National Environmental Research Council (http://www.nerc.ac.uk) with support from the Environment Agency (http://environment-agency.gov.uk).

\section{REFERENCES}

Amoudry LO \& Souza AJ 2011. Deterministic coastal morphological and sediment transport modelling. A review and discussion. Rev. Geophys. 49, 21

Amoudry LO, Souza AJ \& Holt TJ 2009. Sediment transport module for a B-grid coastal shelf ocean model. Coastal Dynamics 2009.

Ashton A, Murray A \& Arnault O 2001. Formation of coastline features by large-scale instabilities induced by high-angle waves. Nature 414, 296-300.

Brown JM, Souza AJ \& Wolf J 2010. An 11-year validation of wave-surge modelling in the Irish Sea, using a nested POLCOMS-WAM modelling system. Ocean Modelling 33 118-28.

Burchard, H., G. Flöser, J. V. Staneva, T. H. Badewien, et al., 2008. Impact of density gradients on net sediment transport into the Wadden Sea, J. Phys. Oceanogr., 38, 566-587, 2008

Chini N, Stansby P, Leake J, Wolf J, et al. 2010a. The impact of sea level rise and climate change on extreme inshore wave climate: a case study for East Anglia (UK). Coast. Eng. 57, 973-84

Chini N, Stansby P, Walkden M, Hall J, et al. 2010b. Modelling long term implication of climate change projection on shore morphology of north Norfolk, UK, combining TOMAWAC and SCAPE. Proc. Int. Conf. Coastal Eng. 2010, Shanghai

Chini N \& Villaret C 2007. Numerical modelling of the morphodynamic evolution of sand banks in the Gironde estuary. 32nd IAHR Congress, Venice

Clough JS \& Park RA 2007. Technical Documentation for SLAMM 5.0. Warren Pinnacle Consulting, Inc.

Cooper N, Barber P, Bray M \& Carter, D 2002. Shoreline management plans: a national review and engineering perspective. Proceedings of the Institute of Civil Engineers, Water and Maritime Engineering, 154, 221-228.

Cooper NJ \& Pontee NI 2006. Appraisal and evolution of the littoral 'sediment cell' concept in applied coastal management: experiences from England and Wales. Ocean Coast. Manage. 49, 498-510

Coulthard TJ, Macklin MG, Kirkby MJ 2002. A cellular model of Holocene upland river basin and alluvial fan evolution. Earth Surf. Proc. Landf. 27 269-88

Cowell PJ, Stive MJ, Niedoroda AW, de Vriend HJ et al M 2003. The coastal tract (part 1): a conceptual approach to aggregated modeling of low-order coastal change. J. Coast. Res. 19, 812-27.

Dearing JA, Richmond N, Plater AJ, Wolf J, et al. 2006. Modelling approaches for coastal simulation based on cellular automata: the need and potential. Phil. Trans. Roy. Soc. A 364, 1051-71

DEFRA, 2006. Shoreline management plan guidance. Volume 1: Aims and requirements. Volume 2: Procedures (plus 10 appendices) March 2006. Department of Environment, Food and Rural Affairs, London, 54pp.

Dickson ME, Walkden MJA \& Hall JW 2007. Systemic impacts of climatic change on an eroding coast over the 21st century. Climatic Change 81, 141-66.

French JR (ed.) (2004) Critical Concepts in Coastal Geomorphology. London, Routledge. 
French JR, Burningham H \& Whitehouse RJ 2010. Coastal system mapping: a new approach to formalising and conceptualising the connectivity of large-scale coastal systems. AGU Fall Meeting 2010 EP23A-0765.

Hall JW, Boyce SM, Wang Y, Dawson RJ, et al. 2009. Sensitivity analysis of hydraulic models. J. Hydr. Eng. ASCE, 135, 959-69.

Hanson SJ, Nicholls RJ, Balson P, Brown I, et al., 2010. Capturing coastal geomorphological change within regional integrated assessment: an outcome-driven fuzzy logic approach. J. Coast. Res. 26, 831-42.

Hibma A, de Vriend HJ \& Stive MJF 2003. Numerical modelling of shoal pattern formation in well-mixed elongated estuaries. Est. Coast. Shelf Sci. 57, 981-91.

Holt J \& Proctor P 2008. The seasonal circulation and volume transport on the Northwest European Shelf: a fine resolution model study J. Geophys. Res. 113, C06021

Horrillo-Caraballo JM \& Reeve DE 2008. Morphodynamic behaviour of a nearshore sandbank system: the Great Yarmouth Sandbanks, U.K. Mar. Geol. 254, 91-106

Inman DL \& Frautschy JD 1966. Littoral processes and the development of shorelines. Proc. Coast. Eng. Spec. Conf., Santa Barbara, California. Amer. Soc. Civ. Eng., 511-36.

IPCC 2005. Guidance Notes for Lead Authors of the IPCC Fourth Assessment Report on Addressing Uncertainties, Intergovernmental Panel on Climate Change

Jay DA \& Musiak JD 1994. Particle trapping in estuarine tidal flows. J. Geophys. Res. 99, 445-61

Karunarathna H, Horrillo-Caraballo JM, Spivack M \& Reeve DE 2011. Analysis of key parameters in a diffusion type beach profile evolution model. Cont. Shelf Res. 31, 98-107.

Karunarathna H, Reeve DE \& Spivack M 2008. Long-term morphodynamic evolution of estuaries: an inverse problem. Est. Coast. Shelf Sci. 77, 385-95.

Keen TR \& Slingerland RL 1993. A numerical study of sediment transport and event bed genesis during Tropical Storm Delia. J. Geophys. Res. 98, 4775-91.

Kirwan ML \& Murray AB 2008. Ecological and morphological response of brackish tidal marshland to the next century of sea level rise: Westham Island, British Columbia. Glob. Planet. Change 60, 471-86

de Kok JL 2001, Engelen G, White R \& Wind HG 2001. Modeling land-use change in a decision support system for coastal zone management. Env. Model. Assess. 6, 123-32

Leafe R, Pethick J \& Townend IH, 1998, Realizing the benefits of shoreline management, The Geographical Journal, 164, 282-290.

Lowe JA, Howard TP, Pardaens A, Tinker et al.,2009. UK Climate Projections science report: Marine and coastal projections. Met Office Hadley Centre, Exeter, UK

Mares C \& Mares I 2003. Improvement of long-range forecasting by EEOF extrapolation using an AR-MEM model. Weather Forecast 18(2): 311-24

Mokrech M, Hanson S, Nicholls RJ, Wolf J, et al 2009. The Tyndall coastal simulator. J. Coast. Conserv. 10.1007/s11852-009-0083-6.

Motyka JM \& Brampton AH 1993. Coastal management: mapping of littoral cells. HR Wallingford Report SR328

Murray AB 2007. Reducing model complexity for explanation and prediction. Geomorphology 90, 178-91.

Murray AB \& Paola C 1994. A cellular model of braided rivers. Nature 371, 54-7

Nicholls, RJ, Dawson, RD \& Day, SA, (Eds.) 2013. Broad Scale Coastal Simulation: New Techniques to Understand and Manage Shorelines in the Third Millennium, Springer, in prep.

North West and North Wales Coastal Group, 2011. North West England and North Wales Shoreline Management Plan SMP2, Halcrow Group Ltd, Swindon, UK. Web accessed on 10/09/2012 http://www.mycoastline.org/documents/smp2/SMP2Main.pdf

Pan S, Reeve D, Davidson M et al 2010. Larger-scale morphodynamic impacts of segmented shore-parallel breakwaters on coasts and beaches: an overview of the LEACOAST2 project. Shore \& Beach 78(4)/79(1), $35-43$.

Reeve DE, Horrillo-Caraballo JM, Magar V (2008) Statistical analysis and forecasts of long-term sandbank evolution at Great Yarmouth, UK. Estuar Coast Shelf Sci 79(3):387-399

Reeve DE \& Li B 2009. Stochastic description of quasi-static beach behaviour. ASCE J. Water. Port. Coast. \& Ocean Eng. 135(4), 144-53

Różyński G 2003. Data-driven modelling of multiple longshore bar evolution and interactions. Coast. Eng. 48, 151-70.

Różyński G \& Jansen H 2002. Modelling nearshore bed topography with principal oscillation patterns. $J$. Waterw. Port C-ASCE, 128(5), 202-15 
Ruddy G, Turley C \& Jones T 1998. Ecological interaction and sediment transport on an intertidal mudflat II. An experimental dynamic model of the sediment-water interface. In: K Black, D Paterson \& A Cramp (eds.) Sedimentary processes in the intertidal zone. Geol. Soc. Lond. Spec. Public. 139, 149-66

San Roman Blanco B Sutherland J \& Harper A 2012. pyxis - a workflow manager for integrated modelling. Proceedings of 10th International Conference on Hydroinformatics, HIC 2012, Hamburg, Germany.

Souza AJ, Bell PS \& Amoudry LO 2010b. Working Toward a Common Strategy for U.K. Sediment Transport Research, EOS.

Souza AJ, Lane, A \& Betteridge KF 2010a. Effects of Asymmetric Strained Stratification on currents turbulence and sediment transport. EOS Trans. AGU 91(26), Ocean Sci. Meet. Suppl., Abstract PO54C-03.

Stansby PK, Huang J, Apsley DD, García-Hermosa MI, et al., 2009. Fundamental study for morphodynamic modelling: sand mounds in oscillatory flows. Coast. Eng. 56, 408-18.

Stansby PK \& Omar Awang MA 1998. Response time analysis for suspended sediment transport, J. Hyd. Res. 36, 327-38.

Suffolk Coastal District Council, 2010. The Suffolk SMP: First Review of Shoreline Management Plan SMP7 (previously Sub-Cell 3C): Lowestoft Ness to Felixstowe Landguard Point web accessed 11/09/2012 http://www.suffolksmp2.org.uk/publicdocuments/finalsmp/SMP\%20May\%202012\%20Proof\%203.pdf

Thorn CE \& Welford MR 1994. The equilibrium concept in geomorphology. Ann. Assoc. Amer. Geogr. 84, 66696.

Valle-Levinson, A., 2008. Density-driven exchange flow in terms of the Kelvin and Ekman numbers. $J$. Geophys. Res., 113, C04001. doi:10.1029/2007JC004144.

Valvo L, Murray AB \& Ashton A 2006. How does underlying geology affect coastline change? An initial investigation. J. Geophys. Res. 111, F02025

de Vriend HJ, Capobianco M, Chesher T, de Swart HE et al 1993. Approaches to long-term modelling of coastal morphology: a review. Coast. Eng. 21, 225-69.

Walkden MJA \& Hall JW 2005. Mesoscale model of the erosion and profile development of soft rock shores. Coast. Eng. 52, 535-63.

Walkden MJA, Hall JW, Dawson RJ, Roche N et al. 2008. Coastal flood risk analysis driven by climatic and coastal morphological modelling. In: Samuels P et al. (eds.) Floodrisk 2008, Proc. Europ. Conf. Flood Risk Manage. Rese. Practice, Oxford, 355-61.

Walkden MJ \& Rossington SK 2009. Characterisation and prediction of large scale, long-term change of coastal geomorphological behaviours: Proof of concept modelling. Environment Agency - SC060074/PR1

Wang B \& Reeve DE. 2010. Probabilistic modelling of long-term beach evolution near segmented shoreparallel breakwaters. Coast. Eng. 57, 732-44.

Werner B 2003. Modelling landforms as self-organised, hierarchical dynamical systems. In: RM Iverson \& P Wilcock (eds.) Prediction in Geomorphology. AGU Geophysical Monograph 135, 131-50.

Whitehouse R, Balson P, Brampton A, Blott S, et al., 2009. Characterisation and prediction of large-scale, longterm coastal geomorphological behaviours: Final Science Report: SC060074/SR2. Bristol, Environment Agency, 281pp.

Wu X \& Hall JW (2012) Joint extreme value analysis of beach level distributions for improved flood risk estimation. Coastal Engineering, in prep. 